\title{
Infection and Hyperinfection with Strongyloides stercoralis: Clinical Presentation, Etiology of Disease, and Treatment Options
}

\author{
Nicolas Barros • Martin Montes
}

Published online: 11 October 2014

(C) Springer International Publishing AG 2014

\begin{abstract}
Human strongyloidiasis is a neglected global parasitic disease that affects large populations, especially in poorer regions of the world. Improved diagnostic tools, including serology and molecular tests, are demonstrating that the prevalence of infection is far higher than previously thought. Most complications arise as a consequence of delayed diagnosis, primarily due to physicians not considering this potentially lethal parasitic infection. The likelihood of developing mild chronic strongyloidiasis or hyperinfection syndrome depends on the status of the host defenses. The critical host responses controlling Strongyloides stercoralis in animal models include eosinophils, neutrophils, and antibodies. Corticosteroid treatment and human T-lymphotropic virus (HTLV)-1 infection predispose to hyperinfection in humans, but how these result in hyperinfection is poorly defined. Improved diagnostic tests and molecular epidemiology are highlighting the underappreciated burden of disease, which could be addressed with mass chemotherapy with proven effective drugs like ivermectin.
\end{abstract}

Keywords Strongyloides - Infection - Hyperinfection · Etiology Parasitic infection . Tropical medicine

\footnotetext{
N. Barros

Department of Internal Medicine, University of Texas Southwestern, Dallas, TX, USA

N. Barros $\cdot$ M. Montes $(\bowtie)$

Instituto de Medina Tropical 'Alexander von Humboldt', Universidad Peruana Cayetano Heredia, Av. Honorio Delgado 430

SMP, Lima, Peru

e-mail: martin.montes@upch.pe

M. Montes

Department of Medicine, Division of Infectious Diseases, University of Texas Medical Branch at Galveston, Galveston, TX, USA
}

\section{Introduction}

Soil-transmitted helminths are ubiquitous in tropical and subtropical areas worldwide. Although it is estimated that one out of every four individuals is affected, 4 billion are at risk of contracting infection $[1,2]$.

Among soil-transmitted helminths, the prevalence of Strongyloides stercoralis infection is usually underestimated and its impact overlooked [3]. Previous reports from 35 years ago suggested that about 30-100 million individuals were infected worldwide [4]. However, a recent report indicates that its prevalence is about $10-40 \%$ within tropical and subtropical countries, but can be as high as $60 \%$ in some areas. Most of these studies have relied on insensitive diagnostic tests like single direct stool examinations [5••].

The prevalence of infection in developed countries is low, mainly because individuals have access to improved sanitation [6]. However, individuals who have temporarily lived or travelled to endemic areas, such as immigrants, tourists, and military personal, are also at risk. Chronic asymptomatic infection may last for decades after exposure [7-9]. Treatment of these individuals with corticosteroids may lead to hyperinfection syndrome [10].

\section{Biology}

S. stercoralis is unique among helminths due to its complex life cycle. It has both a free-living stage and a parasitic cycle. During the parasitic life cycle, the filariform larvae (L3) penetrates the intact skin and travels through the venous circulation until it reaches the lungs, where it invades into the alveolar space. After molding twice, the larvae migrate up the bronchial tree and are then swallowed, reaching the gastrointestinal tract. Once in the duodenum, the larvae penetrate the mucosa, where the females lay embryonated eggs (through 
a process of parthenogenesis not requiring the male). Rhabditoid larvae (L1) hatch from these eggs within the intestinal wall, migrate into the intestinal lumen, and are either shed with the stools or mature into filariform larvae (L3), penetrate the intestinal mucosa or perianal skin and complete a new parasitic cycle. This process, known as autoinfection, is unique to Strongyloides among round worms. In the normal host, shedding of larvae is intermittent and the numbers small. Thus, it is difficult to diagnose by routine stool microscopy. Once in humid soil, the rhabditoid larvae maturate into filariform (L3) larvae and become infective. Alternatively, they can develop into the free-living male and female adults, which reproduce sexually. This allows $S$. stercoralis to survive outside the human host for prolonged periods of time [11].

\section{Pathology}

The burden of disease and clinical manifestations of $S$. stercoralis infection are determined by the complex interaction between the host immune response and the invading pathogen. The innate immune response to parasite infections has been classically described as governed by eosinophils [12]. However, newer reports have shown that both macrophages and neutrophils can work as effector and immunomodulatory cells during Strongyloides infection [13••, 14].

In animal models, eosinophils are able to function as antigen-presenting cells, leading to the induction of the primary immune response $[15,16]$. In addition, S. stercoralis antigens lead to neutrophil activation and recruitment [17]. Although the mechanisms of larval killing are not fully elucidated, both neutrophil myeloperoxidase (MPO) and eosinophil major basic protein (MBP) are required for larval killing [18]. In addition, neutrophils and eosinophils kill larvae through a mechanism dependent on complement component C3 [19]. A recent report showed that infection with $S$. stercoralis leads to the induction of alternatively activated macrophages, which in turn collaborate with neutrophils and complement to kill the parasite [14]. The link between the innate and adaptive immunity is not well defined. Eosinophils are capable of activating antigen-specific lymphocytes and assist in priming of naïve $\mathrm{T}$ cells to initiate type $2 \mathrm{~T}$ helper (Th2) cell responses against infection [12]. Th2 cells in turn produce interleukin (IL)-5, which is essential for further generation and activation of eosinophils [20]. Thus, eosinophils play a pivotal role in linking the innate and adaptive immune response.

Adaptive immunity responses involve the induction and expansion of both antigen-specific $\mathrm{T}$ and $\mathrm{B}$ cells. The expression of IL- 4 and IL- 5 by Th2 cells is important to generate immunoglobulin class switch to immunoglobulin (Ig)-G and $\operatorname{IgE}$ by $B$ cells [21]. In mice infected with $S$. venezuelensis, $\operatorname{IgG}$ and $\operatorname{IgE}$ accelerated expulsion of larva [22]. The importance of IL-4 was also shown by a prior report from an animal model, were the expression of IL-4R was necessary for timely elimination of larva [23]. In addition IL-13 (a Th2 cytokine) increases gut peristalsis and may help in larval expulsion [24].

Regulatory T cells (Tregs) are a unique population of cluster of differentiation (CD)- $4+\mathrm{T}$ cells that are able to modulate immune responses to both self-reactive lymphocytes and foreign antigens. Tregs exert their suppressive function through the production of anti-inflammatory cytokines, cellto-cell contact, and by consumption of pro-inflammatory cytokines. By modulating the immune response, Tregs avoid collateral damage from exuberant responses. However, expansion of this population can decrease Th2 responses, rendering the host susceptible to infections [25]. There is evidence than Tregs play a role in parasitic control. Subjects infected with human T-lymphotropic virus (HTLV)-1 have increased numbers of circulating Tregs [26]. In fact, Strongyloides itself can also increase the number of circulating Tregs, as has been demonstrated in animal models [27•]. An increased number of Tregs could alter the immune balance necessary for efficient parasite eradication. In mice models, Tregs delay expulsion of S. ratti by a suppressed IL-9 response [28]. In the human counterpart, we have previously proved that the increase in the number of Tregs is inversely correlated with IL-5 levels, a key cytokine for eosinophil-mediated response to Strongyloides [29]. In addition, we have found an increase in the number of Tregs in intestinal tissue in patients with strongyloidiasis. This was associated with decreased IgEexpressing cells in areas adjacent to the parasite (unpublished data). Altogether, these data suggest an important role of Tregs in down-regulating an otherwise protective immune response to Strongyloides infection.

\section{Clinical Manifestations}

The presentation of S. stercoralis in immunocompetent patients is usually mild. Initial infection when noted is characterized by a cutaneous reaction as the larvae penetrate the skin, known as ground itch. Subsequently, patients may develop mild cough, wheezing, or Loeffler-like syndrome. Although the spectrum of disease is extensive, the majority of patients present with asymptomatic or mildly symptomatic chronic infections [30].

Chronic infection is characterized by mild abdominal complaints such as discomfort, bloating, nausea, vomiting, and diarrhea [11]. Eosinophilia is found in up to $90 \%$ of the cases, with high levels of IgE in $75 \%$ [31]. A recent report found positive serology to $S$. stercoralis in $5 \%$ of immigrants and travelers to endemic areas [8]. 
In some patients, large numbers of rhabditiform larvae mature into the invasive filariform stage prior to being excreted. These infective L3 larvae can reinvade the intestinal wall or perianal area, creating cycles of auto-infection. In the absence of an effective host response, these cycles lead to massive numbers of organisms (Fig. 1). This process is known as hyperinfection syndrome [32]. Hyperinfection is typically seen in patients on high-dose or chronic corticosteroid therapy, HTLV-1 co-infection, children with malnutrition, or other defects of granulocyte function [33•]. Although HIV-infected individuals may present with decreased levels of CD4+T cells, HIV alone is not associated with hyperinfection syndrome [34].

The majority of cases of hyperinfection syndrome present with abdominal pain and diarrhea [35]. However, they may also develop constipation, ileus, intestinal obstruction, enteritis, and/or gastrointestinal bleeding [36, 37]. Extra-intestinal manifestations are varied and include pulmonary infiltrates, alveolar hemorrhage, and respiratory failure $[38,39]$. In addition, the migration of the parasites through the intestinal wall into the bloodstream leads to translocation of gastrointestinal bacteria. Patients may present with bacteremia and central nervous system infections with enteric organisms including gram-negative bacteria and Enterococcus species [40]. The classic dermatological manifestation is a migratory, linear, and serpiginous lesions (larva currens) [41]. Unlike patients with chronic infection, patients with hyperinfection syndrome present with large numbers of larvae but few eosinophils [32]. The case-fatality rate for hyperinfection syndrome is high (up to $85 \%$ ) [33•].

In the developed countries, corticosteroid recipients account for the majority of cases of hyperinfection syndrome $[10,42,43]$. Patients may develop hyperinfection when corticosteroids are used in treatment of autoimmune diseases, organ transplantation, or treatment of malignancies. Corticosteroids markedly suppress function of eosinophils and other granulocytes as well as aspects of cell-mediated immunity [44]. However, in resource-poor countries the main risk factors for hyperinfection include malnutrition and infection with HTLV-1 [32, 45].

\section{Diagnosis}

In contrast to other intestinal nematodes in which ova can be easily detected in stool, $S$. stercoralis is characterized by low numbers and intermittent larval shedding. A single stool exam yields positive results in, at best, 30-50\%. Examining up to three consecutive stool samples has been shown to improve sensitivity to up to $95 \%$ [46]. Culture in an agar plate has a higher sensitivity ( $96 \%$ ); however, it is laborious and time consuming [47]. In the normal host, the diagnostic stage is the rhabditiform larva. In patients at risk for hyperinfection, the sensitivity of stool examination is higher due to increased parasite load in the stools. In such cases, filariform larvae are more frequently found [46].
Fig. 1 A case of severe strongyloidiasis. The upper right photo shows severe erosion of duodenal mucosa found in an endoscopy for a patient with intestinal sub-occlusion. The left photo shows H-E staining of duodenal biopsy demonstrating multiple parasites invading the intestinal wall. The lower right photo shows Baermann's stool sedimentation with thousands of infective stage (L3) larvae of Strongyloides stercoralis (Courtesy of Carlos Seas MD, UPCH, Lima, Peru)

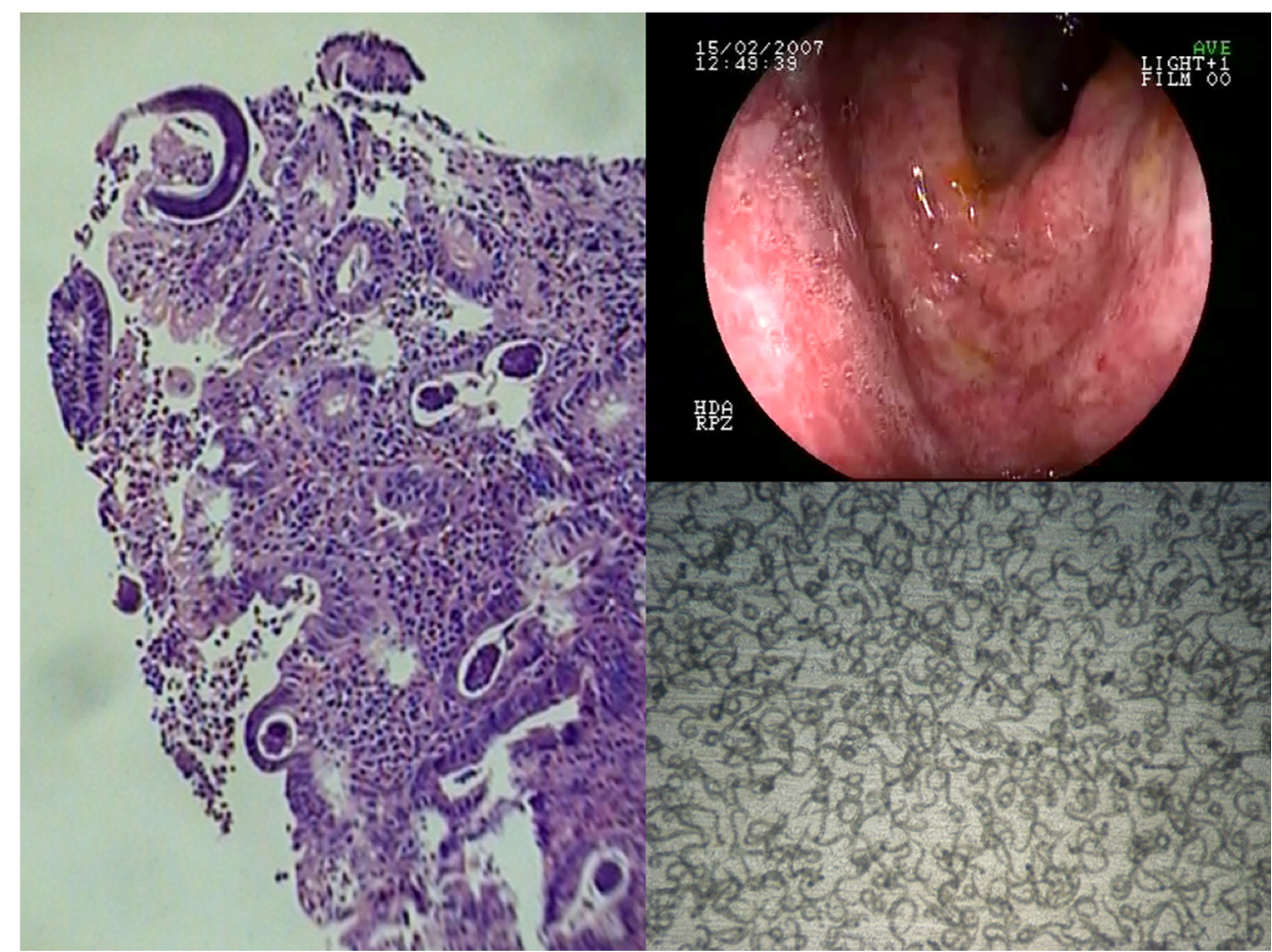


During the past decade, multiple immunological tests have been developed. An enzyme-linked immunosorbent assay (ELISA) test for serum antibodies to multiple $S$. stercoralis antigens has a high sensitivity (83-93\%) and reported specificity (95-98\%). Comparison of the performance of several serological assays has shown that both NIE-LIPS and ELISA tests achieve close to $100 \%$ specificity, maintain sensitivity above $75 \%$, and may be useful epidemiological tools [48, 49.0]. Although the presence of antibodies does not distinguish between past and current infections, a recent report showed seroconversion in up to $80 \%$ of treated patients [49••]. Other problems with conventional ELISA tests include cross-reactivity with other helminthic infections [48]. A coproantigen ELISA test has been developed with high sensitivities and no cross-reactivity to other helminthes [50]. However, the test involves the production of $S$. ratti-specific rabbit polyclonal antibodies, which are only available in research facilities.

Multiple molecular techniques are now available in research facilities. Several reverse transcription polymerase chain reaction (RT-PCR) protocols have been developed with sensitivities and specificities bordering $100 \%$ [51]. Although expensive, these techniques have the advantage that they can be performed in samples that have been previously preserved in ethanol and stored at room temperature [52]. This allows easy transportation to facilities with real-time PCR capabilities.

Loop-mediated isothermal amplification techniques allow for rapid, highly sensitive, and specific molecular diagnosis in the field. Recently, Watts et al. [53•] described a loopmediated isothermal amplification (LAMP) assay for S. stercoralis in stool [53•]. This assay represents a promising new technique for fast and reliable diagnosis in areas with few capabilities.

\section{Treatment}

S. stercoralis infection should always be considered pathological and warrants treatment, regardless of the presence or absence of symptoms. S. stercoralis is susceptible to ivermectin. A single oral dose of $200 \mathrm{mcg} / \mathrm{kg}$ of ivermectin is the preferred regimen [30]. Thiabendazole and albendazole are alternatives.

Multiple trials have compared the safety and efficacy of the oral medications. Ivermectin, in a single dose $(200 \mathrm{mcg} / \mathrm{kg})$ or double doses given 2 weeks apart, was superior to a 7-day course of oral albendazole $800 \mathrm{mg}(93 \%, 97 \%$, and $63 \%$ success rate, respectively) [54]. Ivermectin $200 \mathrm{mcg} / \mathrm{kg}$ at a single dose was similar to twice-daily doses of thiabendazole $25 \mathrm{mcg} / \mathrm{kg}$ for 2 days, but produced fewer side effects [55]. A 7-day course of albendazole $10 \mathrm{mg} / \mathrm{kg} /$ day can be used if the other medications are unavailable, but the cure rates are significantly less (38-45\%) [54]. Both serology and eosinophil counts improve slowly requiring 6 and 12 months to normalize. They can be used as a surrogate marker for treatment success, but are not ideal due to the delays in resolution [56 $6^{\bullet}$.

Whenever hyperinfection syndrome is suspected, antiparasitic therapy is required immediately. Immunosuppression should be reduced when possible. Ivermectin at a daily dose of $200 \mathrm{mcg} / \mathrm{kg}$ daily for up to 2 weeks should be given. Prolonged courses may be required if the patient continues to present signs of persistent infection. Daily stool study follow-up should be taken for at least 2 weeks to assure parasite clearance [33•].

In patients with malabsorption, unable to tolerate oral medications, or with deteriorating clinical status, daily ivermectin $200 \mathrm{mcg} / \mathrm{kg}$ can be given per rectum until able to tolerate oral administration. Other routes of administration include daily subcutaneous injections of veterinary formulations of ivermectin $200 \mathrm{mcg} / \mathrm{kg}$ for at least 2 weeks or until oral medications are tolerated [57]. Subcutaneous versus rectal administration has not been compared in clinical trials. However, rectal absorption of ivermectin is low, and serum concentrations were higher in patients with subcutaneous administration [58]. Neither rectal nor subcutaneous administrations are US Food and Drug Administration approved.

Blood culture surveillance should be taken to exclude bacteremia and meningitis. Mass drug administration for soil-transmitted helminthes has demonstrated a decrease in the prevalence of infection [59]. Most of these programs include mass chemotherapy with benzimidazole antiparasitic drugs, which have limited (albendazole) or no (mebendazole) activity against $S$. stercoralis [60]. However, little information on S. stercoralis impact is available, and deworming programs currently do not include additional measures to effectively target $S$. stercoralis.

\section{Vaccines}

A vaccine against $S$. stercoralis would be helpful in controlling the burden of disease, especially in areas where access to sanitation is limited. Ben Nouir et al. [61] have recently shown that the administration of $S$. ratti heat shock protein 60 conferred partial protection against challenge in mice. Recently, Abraham et al. [62] showed that the Ss-IR antigen (S. stercoralis immune reactive) from $S$. stercoralis is highly antigenic in humans. In addition, mice immunized with the Ss-IR antigen presented an $80 \%$ decrease in the survival of larval parasites during the challenge infection [62].

\section{Conclusion}

S. stercoralis infection is a neglected disease that can cause chronic infection and potentially fatal hyperinfection. 
Hyperinfection is most common in patients who have been treated with corticosteroids or who have HTLV-1 co-infection. Eosinophils and neutrophils are the main host cells controlling the numbers of organisms. Diagnosis is difficult in patients with low numbers of organisms, but novel assays such as realtime PCR are improving diagnosis. Treatment with ivermectin is effective. The data on the global burden of disease are limited by lack of data on prevalence of infection using sensitive diagnostic techniques. Mass chemotherapy with ivermectin could potentially have a major impact on health, but better epidemiologic data are needed to identify areas where mass chemotherapy is appropriate.

\section{Compliance with Ethics Guidelines}

Conflict of Interest Nicolas Barros and Martin Montes declare that they have no conflict of interest.

Human and Animal Rights and Informed Consent This article does not contain any studies with human or animal subjects performed by any of the authors

\section{References}

Papers of particular interest, published recently, have been highlighted as:

- Of importance

-• Of major importance

1. Cappello M. Global health impact of soil-transmitted nematodes. Pediatr Infect Dis J. 2004;23:663-4.

2. Brooker S, Clements AC, Bundy DA. Global epidemiology, ecology and control of soil-transmitted helminth infections. Adv Parasitol. 2006;62:221-61.

3. Olsen A, van Lieshout L, Marti H, Polderman T, Polman K, Steinmann P, et al. Strongyloidiasis-the most neglected of the neglected tropical diseases? Trans R Soc Trop Med Hyg. 2009;103:967-72.

4. Genta RM. Global prevalence of strongyloidiasis: critical review with epidemiologic insights into the prevention of disseminated disease. Rev Infect Dis. 1989;11:755-67.

5.• Schär F, Trostdorf U, Giardina F, Khieu V, Muth S, Marti H, et al. Strongyloides stercoralis: Global Distribution and Risk Factors. PLoS Negl Trop Dis. 2013;7:e2288. This report outlines the global distribution of S. stercoralis. It is probably one of the most complete and evidence-based epidemiological reports in the literature. The authors described the lack of data in multiple areas and they highlight the need for more surveillance in developing countries.

6. Strunz EC, Addiss DG, Stocks ME, Ogden S, Utzinger J, Freeman MC. Water, sanitation, hygiene, and soil-transmitted helminth infection: a systematic review and meta-analysis. PLoS Med. 2014;11:e1001620.

7. Bailey MS, Thomas R, Green AD, Bailey JW, Beeching NJ. Helminth infections in British troops following an operation in Sierra Leone. Trans R Soc Trop Med Hyg. 2006;100:842-6.

8. McCarthy AE, Weld LH, Barnett ED, So H, Coyle C, Greenaway $\mathrm{C}$, et al. Spectrum of illness in international migrants seen at GeoSentinel clinics in 1997-2009, part 2: migrants resettled internationally and evaluated for specific health concerns. Clin Infect Dis. 2013;56:925-33.

9. de Silva S, Saykao P, Kelly H, MacIntyre CR, Ryan N, Leydon J, et al. Chronic Strongyloides stercoralis infection in Laotian immigrants and refugees 7-20 years after resettlement in Australia. Epidemiol Infect. 2002;128:439-44.

10. Chokkalingam Mani B, Mathur M, Clauss H, Alvarez R, Hamad E, Toyoda Y, et al. Strongyloides stercoralis and Organ Transplantation. Case Rep Transplant. 2013;2013:549038.

11. Greaves D, Coggle S, Pollard C, Aliyu SH, Moore EM. Strongyloides stercoralis infection. BMJ. 2013;347:f4610.

12. Rosenberg HF, Dyer KD, Foster PS. Eosinophils: changing perspectives in health and disease. Nat Rev Immunol. 2013;13:9-22.

13.• Galioto AM, Hess JA, Nolan TJ, Schad GA, Lee JJ, Abraham D. Role of eosinophils and neutrophils in innate and adaptive protective immunity to larval strongyloides stercoralis in mice. Infect Immun. 2006;74:5730-8. This paper summarizes the complex immunological mechanism during S. stercoralis infection.

14. Bonne-Année S, Kerepesi LA, Hess JA, O'Connell AE, Lok JB, Nolan TJ, et al. Human and mouse macrophages collaborate with neutrophils to kill larval Strongyloides stercoralis. Infect Immun. 2013;81:3346-55.

15. Padigel UM, Lee JJ, Nolan TJ, Schad GA, Abraham D. Eosinophils can function as antigen-presenting cells to induce primary and secondary immune responses to Strongyloides stercoralis. Infect Immun. 2006;74:3232-8.

16. Padigel UM, Hess JA, Lee JJ, Lok JB, Nolan TJ, Schad GA, et al. Eosinophils act as antigen-presenting cells to induce immunity to Strongyloides stercoralis in mice. J Infect Dis. 2007;196:1844-51.

17. O'Connell AE, Redding KM, Hess JA, Lok JB, Nolan TJ, Abraham D. Soluble extract from the nematode Strongyloides stercoralis induces CXCR2 dependent/IL-17 independent neutrophil recruitment. Microbes Infect. 2011;13:536-44.

18. O'Connell AE, Hess JA, Santiago GA, Nolan TJ, Lok JB, Lee JJ, et al. Major basic protein from eosinophils and myeloperoxidase from neutrophils are required for protective immunity to Strongyloides stercoralis in mice. Infect Immun. 2011;79:2770-8.

19. Kerepesi LA, Hess JA, Nolan TJ, Schad GA, Abraham D. Complement component $\mathrm{C} 3$ is required for protective innate and adaptive immunity to larval strongyloides stercoralis in mice. $\mathrm{J}$ Immunol. 2006;176:4315-22.

20. Spencer LA, Weller PF. Eosinophils and Th2 immunity: contemporary insights. Immunol Cell Biol. 2010;88:250-6.

21. Allen JE, Maizels RM. Diversity and dialogue in immunity to helminths. Nat Rev Immunol. 2011;11:375-88.

22. Matsumoto M, Sasaki Y, Yasuda K, Takai T, Muramatsu M, Yoshimoto T, et al. IgG and IgE collaboratively accelerate expulsion of Strongyloides venezuelensis in a primary infection. Infect Immun. 2013;81:2518-27.

23. Negrão-Corrêa D, Pinho V, Souza DG, Pereira AT, Fernandes A, Scheuermann K, et al. Expression of IL-4 receptor on non-bone marrow-derived cells is necessary for the timely elimination of Strongyloides venezuelensis in mice, but not for intestinal IL-4 production. Int J Parasitol. 2006;36:1185-95.

24. Mannon P, Reinisch W. Interleukin 13 and its role in gut defence and inflammation. Gut. 2012;61:1765-73.

25. Liston A, Gray DH. Homeostatic control of regulatory T cell diversity. Nat Rev Immunol. 2014;14:154-65.

26. Tattermusch S, Bangham CR. HTLV-1 infection: what determines the risk of inflammatory disease? Trends Microbiol. 2012;20:494-500.

27. Blankenhaus B, Klemm U, Eschbach ML, Sparwasser T, Huehn J, Kühl AA, et al. Strongyloides ratti infection induces expansion of Foxp3+ regulatory $\mathrm{T}$ cells that interfere with immune response and parasite clearance in BALB/c mice. J Immunol. 2011;186:4295305. In this study, the authors describe the interaction of S. ratti and the immune system. This is particularly important for 
understanding the chronicity of infection and the development of concomitant immunity.

28. Blankenhaus B, Reitz M, Brenz Y, Eschbach ML, Hartmann W, Haben I, et al. Foxp $3^{+}$regulatory T cells delay expulsion of intestinal nematodes by suppression of IL-9-driven mast cell activation in BALB/c but not in C57BL/6 mice. PLoS Pathog. 2014;10:e1003913.

29. Montes M, Sanchez C, Verdonck K, Lake JE, Gonzalez E, Lopez G, et al. Regulatory T cell expansion in HTLV-1 and strongyloidiasis coinfection is associated with reduced IL-5 responses to Strongyloides stercoralis antigen. PLoS Negl Trop Dis. 2009;3:e456.

30. Montes M, Sawhney C, Barros N. Strongyloides stercoralis: there but not seen. Curr Opin Infect Dis. 2010;23:500-4.

31. Rossi CL, Takahashi EE, Partel CD, Teodoro LG, da Silva LJ. Total serum IgE and parasite-specific IgG and IgA antibodies in human strongyloidiasis. Rev Inst Med Trop Sao Paulo. 1993;35:361-5.

32. Marcos LA, Terashima A, Dupont HL, Gotuzzo E. Strongyloides hyperinfection syndrome: an emerging global infectious disease. Trans R Soc Trop Med Hyg. 2008;102:314-8.

33. Mejia R, Nutman TB. Screening, prevention, and treatment for hyperinfection syndrome and disseminated infections caused by Strongyloides stercoralis. Curr Opin Infect Dis. 2012;25:458-63. This study describes hyperinfection syndrome and disseminated infections. It is relevant as it describes the multiple risk factors and current guidelines of therapy.

34. Siegel MO, Simon GL. Is human immunodeficiency virus infection a risk factor for Strongyloides stercoralis hyperinfection and dissemination. PLoS Negl Trop Dis. 2012;6:e1581.

35. Marcos LA, Terashima A, Canales M, Gotuzzo E. Update on strongyloidiasis in the immunocompromised host. Curr Infect Dis Rep. 2011;13:35-46.

36. Hindy P, Parvin R, Hanna K, Gress F. Strongyloidiasis presenting as duodenal obstruction in a patient infected with human T-cell lymphotropic virus type 1. Gastrointest Endosc. 2011;74:439-41.

37. Shields AM, Goderya R, Atta M, Sinha P. Strongyloides stercoralis hyperinfection presenting as subacute small bowel obstruction following immunosuppressive chemotherapy for multiple myeloma. BMJ Case Rep 2014;2014. doi:10.1136/bcr-2013-202234

38. El-Sameed YA, Beejay N, Al Maashari R. Diffuse alveolar haemorrhage and severe hypoxemia from Strongyloides stercoralis hyperinfection syndrome. Clin Respir J 2014. doi:10.1111/crj.12169

39. Gonzalez-Ibarra F, Chevli P, Schachter L, Kaur M, EivazMohammadi S, Tashtoush B, et al. Strongyloidiasis and diffuse alveolar hemorrhage in a patient with systemic lupus erythematosus. Case Rep Med. 2014;2014:278390.

40. Woll F, Gotuzzo E, Montes M. Strongyloides stercoralis infection complicating the central nervous system. Handb Clin Neurol. 2013;114:229-34.

41. Pichard DC, Hensley JR, Williams E, Apolo AB, Klion AD, DiGiovanna JJ. Rapid development of migratory, linear, and serpiginous lesions in association with immunosuppression. J Am Acad Dermatol. 2014;70:1130-4.

42. Buonfrate D, Requena-Mendez A, Angheben A, Muñoz J, Gobbi F, Van Den Ende J, et al. Severe strongyloidiasis: a systematic review of case reports. BMC Infect Dis. 2013;13:78.

43. Coster LO. Parasitic infections in solid organ transplant recipients. Infect Dis Clin North Am. 2013;27:395-427.

44. Druilhe A, Létuvé S, Pretolani M. Glucocorticoid-induced apoptosis in human eosinophils: mechanisms of action. Apoptosis. 2003;8:481-95.

45. Verdonck K, González E, Van Dooren S, Vandamme AM, Vanham G, Gotuzzo E. Human T-lymphotropic virus 1: recent knowledge about an ancient infection. Lancet Infect Dis. 2007;7:266-81.

46. Schär F, Hattendorf J, Khieu V, Muth S, Char MC, Marti HP, et al. Strongyloides stercoralis larvae excretion patterns before and after treatment. Parasitology. 2014;141:892-7.

47. Machicado JD, Marcos LA, Tello R, Canales M, Terashima A, Gotuzzo E. Diagnosis of soil-transmitted helminthiasis in an
Amazonic community of Peru using multiple diagnostic techniques. Trans R Soc Trop Med Hyg. 2012;106:333-9.

48. Anderson NW, Klein DM, Dornink SM, Jespersen DJ, Kubofcik J, Nutman TB, et al. Comparison of three immunoassays for detection of antibodies to Strongyloides stercoralis. Clin Vaccine Immunol. 2014;21:732-6.

49.• Bisoffi Z, Buonfrate D, Sequi M, Mejia R, Cimino RO, Krolewiecki AJ, et al. Diagnostic accuracy of five serologic tests for Strongyloides stercoralis infection. PLoS Negl Trop Dis. 2014;8: e2640. This study describes the sensitivity and specificity of five serologic tests for S. stercoralis (in-house IFAT, NIE-ELISA, and NIE-LIPS, and the commercially available Bordier-ELISA and IVD-ELISA) It is the most complete report regarding serologic testing for $S$. stercoralis.

50. Sykes AM, McCarthy JS. A coproantigen diagnostic test for Strongyloides infection. PLoS Negl Trop Dis. 2011;5:e955.

51. Levenhagen MA, Costa-Cruz JM. Update on immunologic and molecular diagnosis of human strongyloidiasis. Acta Trop. 2014;135:33-43.

52. Sultana Y, Jeoffreys N, Watts MR, Gilbert GL, Lee R. Real-time polymerase chain reaction for detection of Strongyloides stercoralis in stool. Am J Trop Med Hyg. 2013;88:1048-51.

53. Watts MR, James G, Sultana Y, Ginn AN, Outhred AC, Kong F, et al. A loop-mediated isothermal amplification (LAMP) assay for Strongyloides stercoralis in stool that uses a visual detection method with SYTO-82 fluorescent dye. Am J Trop Med Hyg. 2014;90:30611. This study describes a promising new immunological technique for an accurate diagnosis of S. stercoralis infection. This will provide fast and reliable diagnosis in areas with few capabilities.

54. Suputtamongkol Y, Premasathian N, Bhumimuang K, Waywa D, Nilganuwong S, Karuphong E, et al. Efficacy and safety of single and double doses of ivermectin versus 7-day high dose albendazole for chronic strongyloidiasis. PLoS Negl Trop Dis. 2011;5:e1044.

55. Bisoffi Z, Buonfrate D, Angheben A, Boscolo M, Anselmi M, Marocco $\mathrm{S}$, et al. Randomized clinical trial on ivermectin versus thiabendazole for the treatment of strongyloidiasis. PLoS Negl Trop Dis. 2011;5:e1254.

56. Salvador F, Sulleiro E, Sánchez-Montalvá A, Saugar JM, Rodríguez E, Pahissa A, et al. Usefulness of Strongyloides stercoralis serology in the management of patients with eosinophilia. Am J Trop Med Hyg. 2014;90:830-4. This study shows that serology is useful in the diagnosis of probable strongyloidiasis in patients presenting with eosinophilia. In addition, it shows that serology can also be used for follow-up of treatment response.

57. Donadello K, Cristallini S, Taccone FS, Lorent S, Vincent JL, de Backer D, et al. Strongyloides disseminated infection successfully treated with parenteral ivermectin: case report with drug concentration measurements and review of the literature. Int $\mathbf{J}$ Antimicrob Agents. 2013;42:580-3.

58. Fusco DN, Downs JA, Satlin MJ, Pahuja M, Ramos L, Barie PS, et al. Non-oral treatment with ivermectin for disseminated strongyloidiasis. Am J Trop Med Hyg. 2010;83:879-83.

59. McCarty TR, Turkeltaub JA, Hotez PJ. Global progress towards eliminating gastrointestinal helminth infections. Curr Opin Gastroenterol. 2014;30:18-24.

60. Humphries D, Nguyen S, Boakye D, Wilson M, Cappello M. The promise and pitfalls of mass drug administration to control intestinal helminth infections. Curr Opin Infect Dis. 2012;25:584-9.

61. Ben Nouir N, Piédavent M, Osterloh A, Breloer M. Passive immunization with a monoclonal IgM antibody specific for Strongyloides ratti HSP60 protects mice against challenge infection. Vaccine. 2012;30:4971-6.

62. Abraham D, Hess JA, Mejia R, Nolan TJ, Lok JB, Lustigman S, et al. Immunization with the recombinant antigen Ss-IR induces protective immunity to infection with Strongyloides stercoralis in mice. Vaccine. 2011;29:8134-40. 